\title{
Spatial Mapping of Carbon Stock in Riverine Mangroves Along Amanzule River in the Ellembelle District of Ghana
}

\author{
Lily L. Yevugah ${ }^{1}$, Edward M. Osei Jnr. ${ }^{1}$, John Ayer ${ }^{1} \&$ Joshua Osei Nti. ${ }^{1}$ \\ ${ }^{1}$ Department of Geomatic Engineering, Kwame Nkrumah University of Science and Technology, Ghana \\ Correspondence: Lily L. Yevugah, Department of Geomatic Engineering, Kwame Nkrumah University of \\ Science and Technology, Kumasi, Ghana. E-mail: llyevugah@gmail.com
}

Received: November 12, 2016

Accepted: December 21, 2016

Online Published: January 31, 2017

doi:10.5539/esr.v6n1p120

URL: http://dx.doi.org/10.5539/esr.v6n1p120

\begin{abstract}
Compared to other wetland ecosystems mangroves are well known for their numerous ecosystem services, especially carbon pool. In Ghana, there is limited information on the sequestered carbon in mangroves. There is increasing interest on national climate change mitigation and adaptation plans in mangroves in developing nations, and Ellembelle in the Western Region of Ghana is of no exception. Ellembelle is one of the areas with little information on the size and variation of mangrove carbon stock which needs to be addressed. This research is aimed at determining the carbon stock from the carbon sequestered in mangrove and the areal extent in mangrove forest using remote sensing and allometric equation. The ecosystem carbon density estimate for the mangrove forest was weighted based on their spatial distribution across the landscape to yield a total carbon stock of for the Ellembelle mangrove forest. The error obtained from the $95 \%$ Confidence Interval was $\pm 1.53 \%$, which is within the acceptable levels of uncertainty based on the Monte Carlo Analysis. The overall carbon estimated for 2015 based on the area for mangrove ( $374.49 \mathrm{ha})$ was $1.550 \mathrm{Mt}$ with an uncertainty of $\pm 57.125 \mathrm{Kt}$ indicating a high amount of carbon sequestered in mangroves.
\end{abstract}

Keywords: carbon stock, mangrove, uncertainty

\section{Introduction}

Mangrove forests are considered as one of the world's most productive ecosystem (Kathiresan \& Qasim, 2005). Mangrove tree have unique adaptation to the severe conditions of coastal environments. Research shows that mangrove forests are rated as one of the carbon richest forest in the forest. Mangroves swamp with its wealth in stored carbon provides a potential sink for atmospheric carbon. If mangroves are not well catered for, they may become the sources of Green House Gases (GHG) in the likes of carbon and methane. It is therefore necessary to know the amount of carbon sequestered in mangrove.

According to Donato et al. (2011), mangrove forest in the tropics contains an average of 1023 tons carbon per ha. According to Donato et al. mangroves forests in the tropics, contains an average of 1,023 tons carbon per ha. In the case of deforestation mangroves are recorded to give out about $0.02-0.12$ Pg Carbon per year, while storing up to about $20 \mathrm{Pg} \mathrm{C}$ every year. Mukherjee, 2007 indicates that mangrove forest are practically highest sequesters of carbon and their ability to sequester carbon reduces as they reach maturity. Compared to other forest wetland ecosystems, salt marshes, mangroves and sea grass beds, can store large amount of carbon. This is possible for two main reasons: (1) Plants usually grow a lot each year, and for that reason a large amount of Carbon Dioxide $\left(\mathrm{CO}_{2}\right)$ is sequestered; and (2) the soils are without oxygen so carbon that gets incorporated into the soils decomposes quite slowly and can persist for hundreds or even thousands of years (NOAA, 2016).

Mangroves absorbs more carbon than they emit. Knowing the amount of carbon sequestered is usually done by measuring directly on the field, the biomass of dried plant species. There are many conventional methods that are used for quantification of stored carbon. Most of these methods are labour and cost intensive in terms of the coverage. These limitations hinder comprehensive calculation and monitoring of carbon. Appropriate and cost effective methods are required to reduce the laborious method of manually calculating for the amount of carbon sequestered. There should be a good but cost effective means of determining the amount of carbon sequestered. Remote Sensing (RS) is noted for giving a good classification of mangroves. Therefore, integrating RS and Geographic Information Systems (GIS) will be an option in this regard. According to Sellers et al. (1995) and Bastiannssen et al. (1998), RS have been used for the estimation of plant biomass. RS approach can be used for 
carbon sequestration by establishing permanent sample plots by making use of fixed coordinates (MacDicken, 1997). Tucker (1979), Richardson et al. (1983) and Christensen \& Goudriaan (1993) have shown that Near Infra-Red (NIR) radiation contains significant details about plant biomass. Remotely sensed satellite data can therefore be used to compute the biomass and eventually carbon sequestration value of mangrove in a larger area. RS saves time and money (Tripathi et al., 2010). RS and GIS coupled with allometric equation will serve a good to determining biomass of the entire area. Allometric equations for mangroves have been developed for several decades to calculate biomass and subsequent growth. Most studies have used allometric equations for single stemmed tree forms, as mostly seen in Rhizophora, Avicennia and Excoecariaspecies (Clough, 1998).

In recent times, there are reports on commercially harvesting for pulp, wood chip for charcoal production. However as to how much carbon is sequestered in mangrove is not known, leaving questions to how much carbon is being emitted by the harvesting of mangrove and the potential repository of carbon lost if mangroves are maintained and encouraged to grow. The research is based on the integration of RS and GIS in estimating the spatial extent of mangrove to determine how much carbon is stored in mangrove in the study area.

\section{Study area}

The study area is located at the mangrove site along the Amanzule River in Ellembelle in the Western region of Ghana (Figure 1). The study area covers an area of 1824.03 hectares.

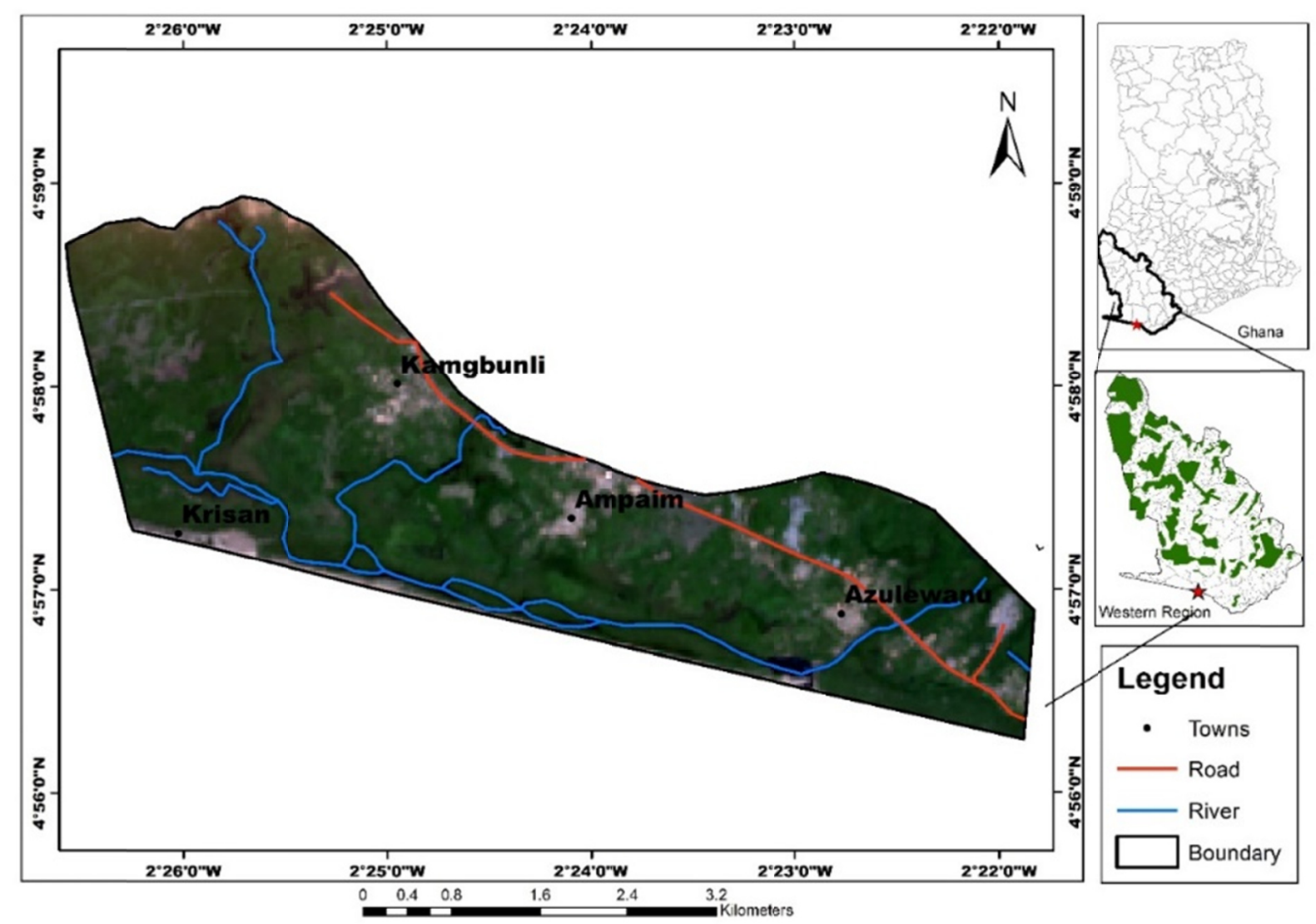

Figure 1. Study area

The area forms part of Greater Amanzule Wetland in the Nzema traditional area, an important wetland ecosystem in Ghana (Figure1). The mangrove forest is estuarine or riverine because it is found along the Amanzule River which meets the sea at Amanzule estuary.

\section{Methodology}

\subsection{Field Work and Data Collection}

An extensive field work was carried out on the area of study. The purpose of the field work was to measure the AGB of the study area. Location data were also collected using a Garmin handheld GPS for training data and accuracy assessment. Google Earth Imagery were used for visual inspection. The GPS points collected were 
converted to KMZ format which is acceptable by Google Earth to enable the validation of the land cover. Based on the measurement, in situ data will be obtained and estimation of carbon stock can be made. Variety of information including positional and allometric measurement were collected. The data collected were relative to the adult, dead standing, dead downed and juvenile mangroves. The data was collected along a transect line drawn within the area of study.

\subsection{Transect Line}

A transect line was made along the stretch of the study area. Due to the marshy grounds, accessibility to some part of the mangrove forest was not possible hence a uniformed distance for choosing sites along the transect line was not achieved. A distance of approximately 100meter was used in assigning plot location. Each plot was randomly selected and plotted into a $20 \mathrm{~m}$ by $20 \mathrm{~m}$ ( $0.4 \mathrm{ha})$. An inner plot of $5 \mathrm{~m}$ by $5 \mathrm{~m}(0.1 \mathrm{ha})$ was created within the $20 \mathrm{~m}$ by $20 \mathrm{~m}$. The 50 meter tape measure was used to measure out the plot. The positional location of the plot was taken to create Permanent Sample Plots (PSP) in order that the plots could easily be relocated and also plotted.

\subsection{Data Collection for Mangroves}

Three of the carbon pools were concentrated upon, 1. AGB of live mangrove (adult and juvenile mangrove 2.BGB of live vegetation 3. Dead wood (dead downed wood and dead standing)

Adult mangrove trees found within the boundary of the $20 \mathrm{~m}$ by $20 \mathrm{~m}$ boundary were measured. Measurements were taken with a Diameter tape. The measurement of the biophysical parameters DBH measurement were taken and recorded as well as the canopy height of the mangrove forest. DBH Measurements were taken at $1.3 \mathrm{~m}$ about ground level. Within the plot area of the data collection for the Adult mangrove, the same area was used in collecting the data for trees that were dead standing or dead and downed wood. The diameters for both the base and the tip were measured.

Sampling juvenile mangroves within a plot were based on a sub-plot with dimension of 5 meter by 5 meter as shown in Figure 2.

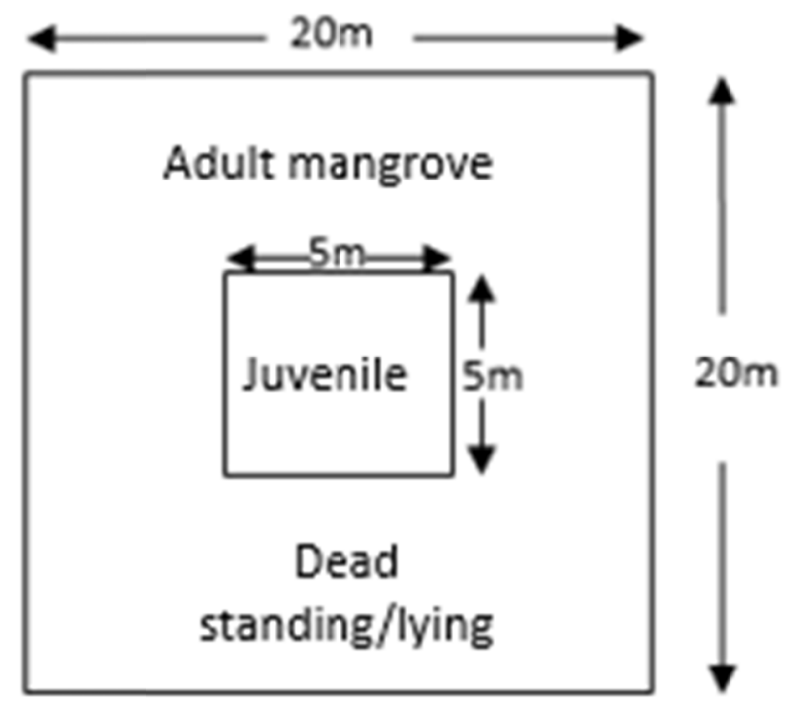

Figure 2. Plot dimension

\subsection{Diameter Measurement}

DBH was measured using a diameter tape. The diameter tape is calibrated in a way to convert the girth of the tree into its diameter, meaning that there was no need to recalculate and convert the reading taken into the DBH from the girth of the mangrove tree; a direct diameter reading is taken. Readings of the breast height of a tree was measured at $1.3 \mathrm{~m}$ above the ground (Figure 3). Taping around the girth was done by stretching the tape firmly against the trunk. When abnormities such as the prop roots prevent a measurement from being taken an appropriate height was chosen by following the procedure shown in Figure 3. 

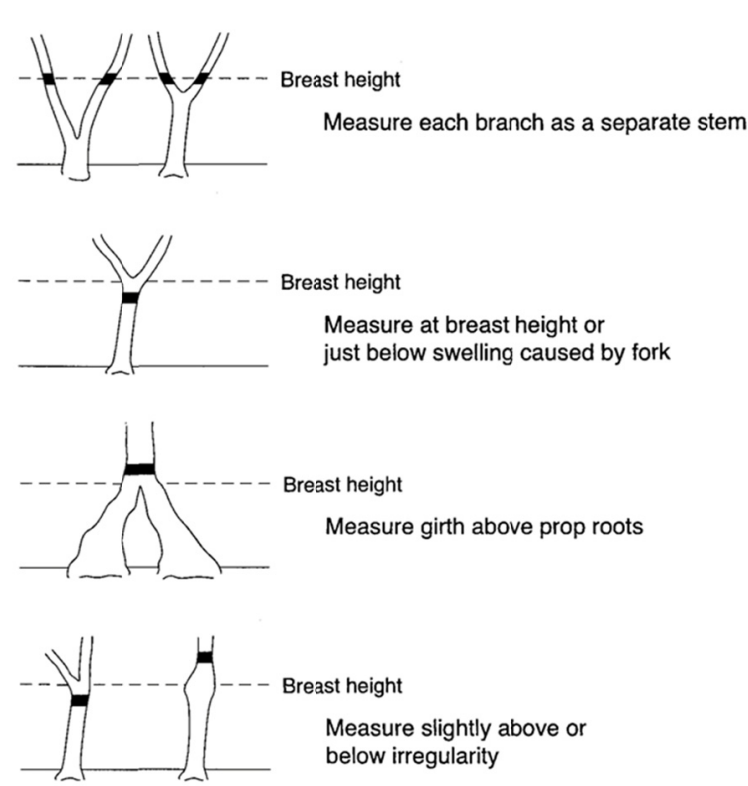

Figure 3. Method for measuring DBH on trees with unusual or different growth forms

(Source English et al., 1997)

In measuring, trees that props below $1.3 \mathrm{~m}$ were measured separately as individual tree. Trees that propped above $1.3 \mathrm{~m}$ was considered as a single tree. Trees with prop roots just below the breast height were also considered a single tree and measured as such. Trees with irregularity occurring at the breast height level were measured slightly above or below irregularity.

\subsection{Equation for Calculating $A G B, B G B, A G C$ and $B G C$}

The AGB was measured using the allometric equations. This was based on the tree DBH and density of the specie Rhizophora mangle. The various allometric equation have been developed for mangrove by the CSIR and Forestry Commission of Ghana.

Table 1. Equation for calculation of Biomass and Carbon.

Above Ground Biomass

$$
A G B=a * p\left(D^{2}\right)^{b}
$$

$$
\mathrm{AGB}=\mathrm{Vol} * \rho * 0.001
$$

Dead Downed Wood

$$
A G B=\sum_{\rho}^{3} V_{\text {olot,class }} * \text { Dens }_{\text {class }}
$$

$\operatorname{AGB}(\mathrm{a}=0.204, \mathrm{~b}=1.225, p=$ wood density, $\mathrm{D}=\mathrm{DBH})$

$\mathrm{BGB}(\mathrm{a}=9.6404, \mathrm{~b}=0.2523)$

$A G C=\left[\frac{\frac{A G B}{1000}}{\text { Area }} * \frac{1}{0.48}\right] B G C=\left[\frac{\left(\frac{B G B}{1000}\right) *\left(\frac{1}{0.04}\right)}{0.48}\right]$ AGC - Above Ground Carbon, BGC - Below Ground Carbon 
Uncertainty $=95 \%$ CI half - width $=(2 * S E)$

Uncertainty $(\%)=100 * \frac{(95 \% \mathrm{CI} \text { half-width })}{\text { mean }}$

Area $=\mathrm{M} * \mathrm{Cm} \quad(\mathrm{m}=$ total carbon area, Estimated carbon

95\%CI half - width for carbon stock for projected area

$$
=\text { Area } * \mathrm{TCS} * \sqrt{(}\left(\square\left(\llbracket 95 \% C I \nabla_{-} C 1 / \text { Area }\right) \rrbracket^{\wedge}+\left(\llbracket 95 \% C I \nabla_{-} C 1 / T C S\right)\right)
$$

Area $=$ estimated land area in mangrove (ha), TCS = mean stand-level carbon stock of the mangrove (Mg ha-1),

$95 \% \mathrm{CI}=$ the uncertainty of each parameter (expressed as $95 \% \mathrm{CI}$ half width).

Equation for uncertainty and carbon stock determination were adapted from working paper 86 of Kauffman and Donato (2012).

\section{Result}

\subsection{Classification of Study Area}

A classified image of for the year 2015 was obtained for the study area. The classification was done in $\mathrm{R}$ using random forest algorithm. It resulted with an accuracy of 81.13 and a kappa of 0.76 . The results from the classification as shown in Figure 4. Indicated the entire area of study was 1824.03 ha with the total area covered by mangrove being 374.49 ha. From field observation of the mangrove stretch the dominant mangrove species in the mangrove forest was the Rhizophora Mangle.

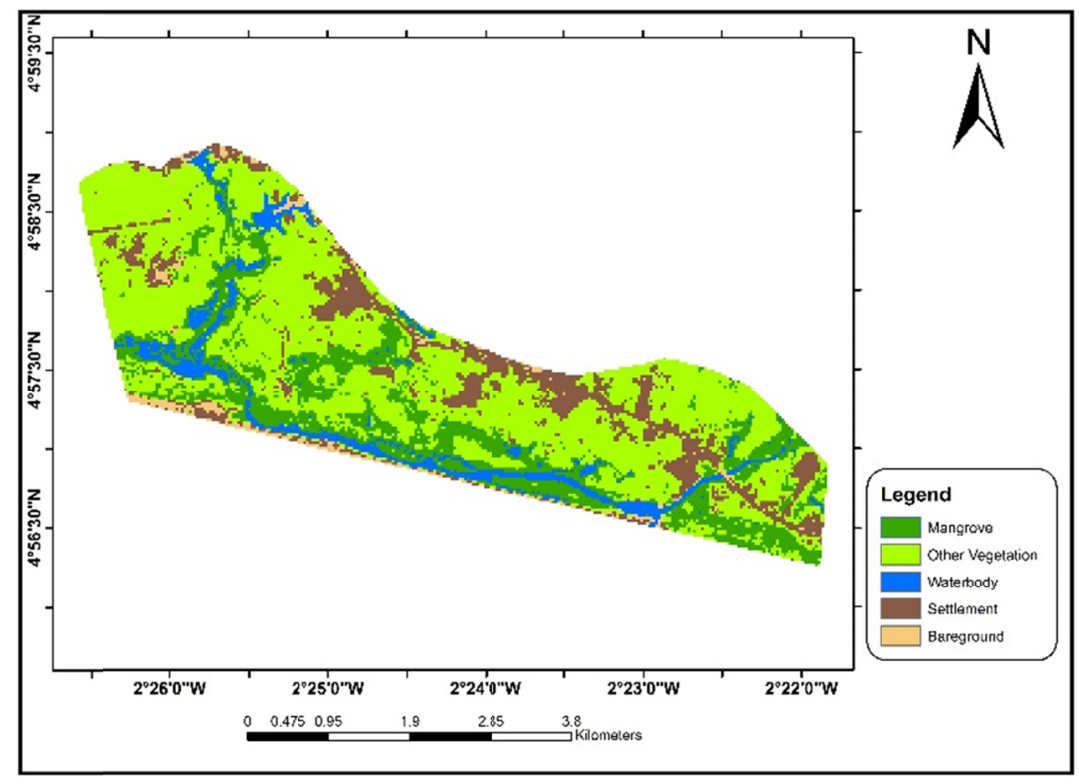

Figure 4. Classified map of study area using Landsat satellite image 2015

\subsection{Carbon Content in Mangrove}

A total of 27 sites where selected along the transect line. The results obtained from the carbon sequestered in mangroves from each site is shown in Figure 4, Most of the sites were covered with Rhizophora mangle. Plot S is as mixture of red and white mangrove (Laguncularia racemosa) and dominant amongst all the plots are the Rhizophora mangle. Plot K recorded the highest sequestered Above Ground Carbon (AGC) of 10689.72 tons/ha and Below Ground Carbon (BGC) of 393.1255 tons/ha as against the Plot G which recorded the lowest AGC of about 6.979117 ha and BGC of 11.46096 tons/ha. Fewer mangroves were recorded within plots G resulting with an AGC of 6.98 tons/ha and 11.46 per ha of BGC. Mangrove in plot K, however, had the highest number of 
mangroves. The total carbon was converted to Carbon Dioxide Equivalent $\left(\mathrm{CO}_{2} \mathrm{e}\right)$ by multiplying it with 3.67 which is the ratio of molecular weights between carbon dioxide and carbon. A total of 38,139.7 tons for the AGB of all carbon pool was calculated and BGB also for all the carbon pool was 4,917.681 tons summing up to a total of 43055.56 tons of Carbon (Figure 5).

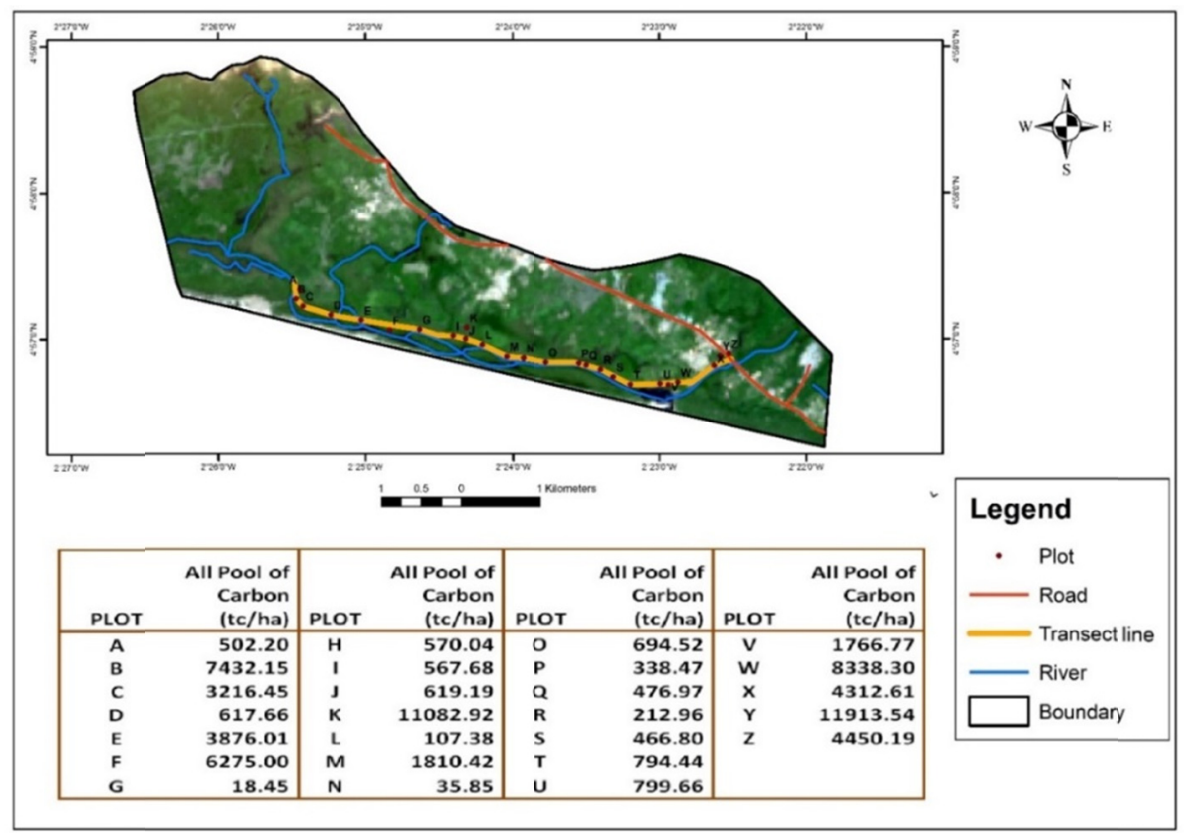

Figure 5. Carbon stock map of mangrove forest.

Using the Intercontinental Panel on Climate Change (IPCC) standard in tracking and predicting emissions of carbon from land cover change approach, the potential emissions that occurred with the mangrove was calculated. The carbon emission obtained from all the sites is 158,014 tons of $\mathrm{CO}_{2} \mathrm{e}$. The level of uncertainty obtained from individual carbon pool were large hence made it impossible to use the simple propagation of error.

A Monte Carlo simulation of 50000 iterations was applied to the uncertainties to determine the uncertainty of the total stand level carbon stock (Figure 6). The uncertainty calculated at 95\%CI was within the range of \pm 152.55 $\mathrm{ha}^{-1}$ which falls within the acceptable $95 \% \mathrm{CI}$ of \pm 1.53 .

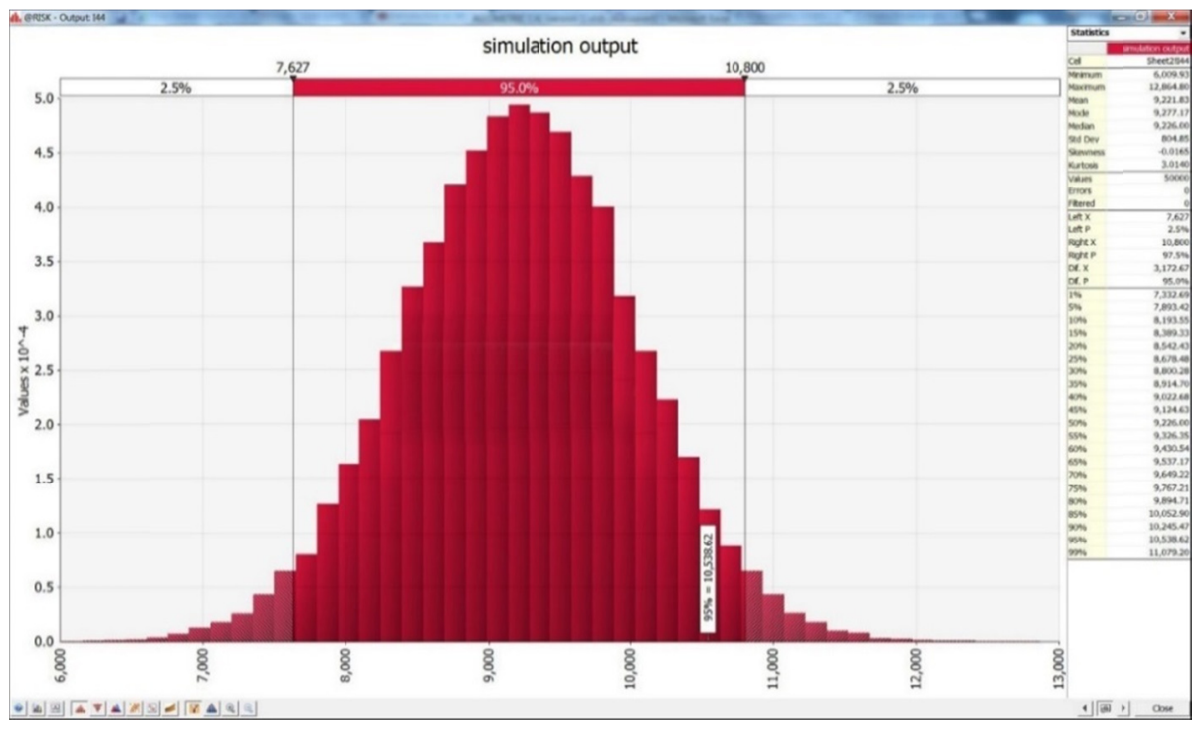

Figure 6. Simulation output of uncertainty for all the carbon pool. 
Total carbon stock of the study area was estimated by finding the product of the carbon stock and the area of the study area. This gave a total of $1,550,295$ tons with and uncertainty of $+57,125$ tons. The results are shown in the Table 2.

Table 2. Sequestered carbon in Mangrove from AGC and BGC.

\begin{tabular}{|c|c|c|c|c|c|c|c|}
\hline \multirow[b]{2}{*}{ PLOT } & \multicolumn{2}{|c|}{ ADULT MANGROVE } & \multicolumn{2}{|c|}{ JUVINILLE MANGROVE } & \multirow{2}{*}{$\begin{array}{c}\text { Dead Standing } \\
\text { AGC }\end{array}$} & \multicolumn{2}{|c|}{ Dead downed } \\
\hline & AGC & BGC & AGC & BGC & & BGC & overall Carbon \\
\hline $\mathbf{A}$ & 338.3696 & 160.3945 & 0.070658 & 3.367897 & & & 502.2026 \\
\hline B & 7064.71 & 366.8216 & & & & 0.619471 & 7432.151 \\
\hline $\mathbf{C}$ & 2887.078 & 329.3722 & & & & & 3216.45 \\
\hline D & 457.2802 & 160.3773 & & & & & 617.6574 \\
\hline $\mathbf{E}$ & 3314.337 & 561.6769 & & & & & 3876.014 \\
\hline $\mathbf{F}$ & 5679.227 & 595.7749 & & & & & 6275.002 \\
\hline G & 6.979117 & 11.46096 & & & & 0.010693 & 18.45077 \\
\hline $\mathbf{H}$ & 446.8494 & 120.8243 & 0.037695 & 1.721327 & & 0.606302 & 570.039 \\
\hline I & 446.8494 & 120.8243 & & & & 0.009792 & 567.6835 \\
\hline $\mathbf{J}$ & 419.4985 & 199.6943 & & & & & 619.1928 \\
\hline $\mathbf{K}$ & 10689.72 & 393.1255 & & & 0.077593 & & 11082.92 \\
\hline $\mathbf{L}$ & 83.85302 & 23.52662 & & & & & 107.3796 \\
\hline $\mathbf{M}$ & 1756.314 & 54.10233 & & & & & 1810.417 \\
\hline $\mathbf{N}$ & 29.13889 & 6.7136 & & & & & 35.85249 \\
\hline $\mathbf{O}$ & 536.8514 & 157.6721 & & & & & 694.5235 \\
\hline $\mathbf{P}$ & 220.5533 & 117.9149 & & & & & 338.4682 \\
\hline $\mathbf{Q}$ & 331.0674 & 145.9029 & & & & & 476.9703 \\
\hline $\mathbf{R}$ & 164.5711 & 48.3907 & & & & & 212.9619 \\
\hline $\mathbf{S}$ & 321.8661 & 144.9328 & & & & & 466.7989 \\
\hline $\mathbf{T}$ & 625.83 & 168.6083 & & & & & 794.4383 \\
\hline $\mathbf{U}$ & 612.24 & 187.4155 & & & & & 799.6556 \\
\hline $\mathbf{V}$ & 557.5796 & 180.2029 & & & & & 737.7825 \\
\hline W & 299.7717 & 184.103 & & & & & 483.8748 \\
\hline $\mathbf{X}$ & 242.5394 & 147.7103 & & & & & 390.2497 \\
\hline $\mathbf{Y}$ & 338.3696 & 160.3945 & & & & & 498.7641 \\
\hline $\mathbf{Z}$ & 265.0002 & 164.6547 & & & & & 429.6548 \\
\hline Grand Total & & & & & & & 43055.56 \\
\hline Mean & 1466.786 & 188.9458 & 0.054176 & 2.544612 & 0.077593 & 0.311565 & \\
\hline StDev & 2575.231 & 148.5882 & 0.023308 & 1.164301 & 0.077593 & 0.347978 & \\
\hline Uncertainty & 0.692 & 5.397334 & 5220.768 & 111.1536 & 2577.545 & 1283.843 & \pm 1.53 \\
\hline
\end{tabular}

Table 3 show the output for the parameters that gave the total carbon stock estimated for the mangrove area of in 2015. The area covered by mangrove was obtained from the classified image of 2015.

Table 3. Table showing estimated carbon stock for the whole mangrove site

\begin{tabular}{lr}
\hline Parameters & $\mathbf{2 0 1 5}$ \\
\hline Total Mangrove Area & 374.49 \\
Total Area of carbon stock level & $4,139.97$ \\
uncertainty of Carbon Stock area per ha & \pm 152.55 \\
carbon stock of the whole area & $1,550,295.00$ \\
Uncertainty of the whole area & $\mathbf{+ 5 7 , 1 2 5 . 4}$ \\
\hline
\end{tabular}

The study revealed that the carbon sequestered in each plot is relatively high, depending on the biomass sequestered at the plot. The carbon calculated for each plot is based on the AGB and the BGB, the dead downed wood and the dead standing. These do not give a comprehensive sum total of the carbon pool as the soil and 
litter were not considered a part of the carbon pool in this study. Most of the sampled plot had no juvenile plant recorded below $1 \mathrm{~cm}$ DBH except for plots A and Plot $\mathrm{H}$. The presence of dead standing is recorded only in Plot $\mathrm{K}$ and dead downed wood were recorded in Plots B, G, H and I. The absence of the dead downed wood and the dead standing wood can be attributed to the sensitization given to the people to make use of the dead downed and the dead standing biomass for firewood. It is therefore evident that with time there will be no dead downed woods and as such the living biomass will be the next option.

Plot G recorded the least AGC. This is due to less mangrove tree within the plot. The population of mangrove in plot $\mathrm{K}$ is more, giving an indication of high carbon in plot $\mathrm{K}$. Plot $\mathrm{K}$ has rich mangrove stand with dense canopy. Mangrove in this section is bigger with average of $10 \mathrm{~cm} \mathrm{DBH.} \mathrm{Comparing} \mathrm{Plot} \mathrm{K} \mathrm{to} \mathrm{the} \mathrm{other} \mathrm{plots,} \mathrm{it} \mathrm{observed}$ less disturbance as there were presence of dead standing wood. This is because it is farther from the river. These contributed to the high Carbon obtained in Plot K. Again, it was observed that mangrove with DBH greater than $10 \mathrm{~cm}$ sequesters more carbon.

The juvenile plants dead downed and the dead standing plants resulted in a higher uncertainty since the data collected per the plot size were few. Due to the large uncertainty, it was inappropriate to use a simple propagation of error to determine uncertainty of the carbon hence the use of the Monte Carlo simulation to normalize the uncertainty (Goslee et al., 2010). The summation of all the uncertainty of the carbon pool was used to simulate and determine the $95 \% \mathrm{CI}$ of the data which was $\pm 1.53 \%$. The common choice for confidence level was $95 \%$ and the level corresponded to percentage of area of the normal curve and the probability of observing a value outside the area is less than 0.05 (Goetz et al., 2009). This was because the normal curve obtained was symmetrical and half of the area was in the right side of the curve and the other half was in the left side of the curve. The CI gave an estimated range of values showing that the probability that the CI will contain the true parameter value for carbon, falls within the $95 \% \mathrm{CI}$.

\section{Conclusion}

The total area occupied by mangrove in 2015 was 374.49 ha therefore gave an estimate of a total carbon stock of $1,550,294.566$ tons $(1.55 \mathrm{Mt})$ and the equivalent carbon emission was 5,689,581.057 tons CO2e (5.690Mt CO2e). The uncertainty of the estimated carbon stock falls within $+57,125$.4tons $(57 \mathrm{Kt})$. From the results obtained, more sample plots and a complete assessment of the remaining carbon pools such as the litter and the soil will improve upon the estimated sequestered carbon. Nonetheless the research shows that the mangrove forest in the Ellembelle District sequesters a large amount of carbon and the availability of mangrove biomass carbon is helpful for the supervision of activities and also for the resilience of mangrove to changing environment. Deforestation of mangrove will however lead to loss in mangrove and loss of a good carbon sink.

\section{Recommendation}

Further research should be carried out on the BGB of the root, soil carbon and litter to understand the carbon sequestration over the entire mangrove ecosystem so that a full application for calculating the carbon stock can be utilized. BGB used in this research was based on the AGB calculated. Any error in the AGB could affect the BGB.

Future carbon stock map could be refined with a well distributed plot evenly across the mangrove area.

\section{References}

Christensen, S., \& J. Goudriaan. (1993). Deriving Light Interception and Biomass from Spectral Reflection ratio. Remote Sensing Environment, 39, 141-152. http://dx.doi.org/10.1016/0034-4257(93)90066-7

Clough, B. F. (1998). Mangrove forest productivity and biomass accumulation in Hinchinbrook channel. Mangroves and Salt Marshes 2, (pp. 191-198) http://dx.doi.org/10.1023/A:1009979610871

Donato, D. C., Kauffman, B. J., Murdiyarso, D., Kurnianto, S., \& Stidham, M. (2011, April 3). Mangroves among the most carbon-rich forests in the tropics. Nature Geoscience: http://www.nature.com/naturegeoscience. Retrieved from Nature of Geoscience. http://dx.doi.org/10.1038/ngeo1123

Goetz, S. J., Laporte, N. T., Johns, T., Walker, W., Kellndorfer, J., Houghton, R. A., \& Sun, M. (2009). Mapping and monitoring carbon stocks with satellite observations: a comparison of methods. Carbon Balance and Management. http://dx.doi.org/10.1186/1750-0680-4-2

Goslee, K., Walker, S. M., Grais, A., Murray, L., Casarim , F., \& Brown, S. (2010). Leaf Technicial Guidance Series for the development of a forest carbon monitoring system for REDD+: Module C-CS: Calculations for Estimating Carbon Stocks. Winrock International. 
Kathiresan, K., \& Qasim, S. Z. (2005). Biodiversity in mangrove ecosystems. New Delhi: Hindustan Publishers, 251.

Kauffman, J. B., \& Donato, D. C. (2012). Protocols for the measurement, monitoring and reporting of structure, biomass and carbon stock in mangrove forests. Working paper 86. CIFOR, Bogor, Indonesia, 1-36. http://dx.doi.org/10.17528/cifor/003749

MacDicken, K. (1998). A guide to monitoring Carbon Storage in Forestry and Agroforestry projects. Winrock International, 5-80.

NOAA. (2016, May 31). NOAA Habitat Conservation | Coastal Blue Carbon. Retrieved from http://www.habitat.noaa.gov/coastalcarbonsequestration.html

Richardson, J., Everit, J. H., \& Gausman, H. W. (1983). Radiometric estimation of Biomass and N-content of Alicia Grass. Remote Sensing Environment, pp. 179-180. http://dx.doi.org/10.1016/0034-4257(83)90021-4

Sellers, P. J., Meeson, F. G., Hall, G., Asrar, R. E., Murphy, R. A., Schiffer, F. P., ... Schimel, P. D. (1995). Remote Sensing of the land surface for studies of global change : Models - Algorithms - Experiments. Remote Sensing Environment, 51, 3 -26). http://dx.doi.org/10.1016/0034-4257(94)00061-Q

Tripathi, S., Soni, K. S., Maurya, K. A., \& Soni, K. P. (2010). Calculating Carbon sequestration using remote sensing and GIS. Geospatial world.

Tucker, C. J. (1979.). Red and Photographic Infrared Linear Combination for Monitoring Vegetation. Elsevier North Holland Inc., 8, 127-150. http://dx.doi.org/10.1016/0034-4257(79)90013-0

\section{Copyrights}

Copyright for this article is retained by the author(s), with first publication rights granted to the journal.

This is an open-access article distributed under the terms and conditions of the Creative Commons Attribution license (http://creativecommons.org/licenses/by/4.0/). 